Military Technical College

Kobry El-Kobbah, Cairo, Egypt

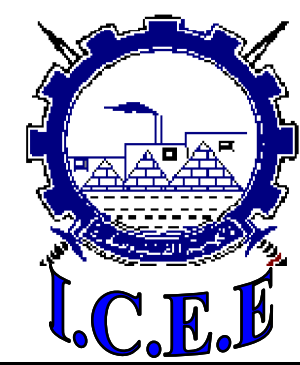

PT-4 $5^{\text {th }}$ International Conference on

Chemical \& Environmental

Engineering

\title{
APPLICATION OF HTPB RUBBER MODIFIER FOR HIGH TEMPERATURE EPOXY ADHESIVE FORMULATIONS.
}

\author{
Eyad S. Khalaf*, Assem H. Hassan *, Saeed M. Hassanein*, and Mostafa K. Hadhoud*
}

\begin{abstract}
Epoxy resins are widely utilized as high performance thermosetting adhesives. Polyamide cured epoxies provide improved flexibility, moisture resistance, and adhesion. Moreover, Versamid could provide lower viscosity, better compatibility, and better cure profiles under adverse conditions. Thus, the use of polyamide (Versamid 125) as a curing agent and HTPB as an elastomeric rubbery modifier give this study an importance in formulating adhesives to be used in high temperature applications. A systematic study has been conducted to investigate the modification of DGEBA-based epoxy systems by the incorporation of hydroxyl-terminated polybutadiene (HTPB) as an elastomeric rubbery modifier in different proportions $(0.75,1.5,2.5,5$, and $10 \%$ by weight) into an epoxy resin. Mechanical mixing process, accompanied with vacuum to get rid of cavitations, was employed to disperse the particles homogeneously into the resin system. Thermal and mechanical properties of the composite and the neat resin were measured with DSC, Zwick universal test machine, and Zwick durometer hardness tester. The composite shows an improvement in stress, strain, shore D hardness, flexural and compressive values. Nearly $2.5 \%$ of HTPB was quite enough to obtain a compromise of the desired mechanical and thermal properties. The detected decrease in $\mathrm{T}_{\mathrm{g}}$ as the rubber content increases means that this modifier can enhance plasticity of the matrix. Reduction in the cross-linking density of the thermoset because of the added modifier has been confirmed and explained.
\end{abstract}

\section{Keywords}

Epoxy resins/ Adhesives/ Modifiers/ Thermal and mechanical properties / HTPB.

\footnotetext{
* Egyptian Armed Forces
} 


\section{INTRODUCTION}

One of the composite materials for technical applications may be represented by thermoset polymer matrix, epoxy resins, which already covers along some of the demanded properties. Epoxy resins are a class of versatile thermosetting polymers, which are widely used in structural composites, adhesives, surface coatings and electronic circuit board laminates [1]. However, the polymer matrix must withstand high mechanical loads; it is usually reinforced with fillers. The addition of different fillers favourably stiffens the material and may also increase the strength under certain load conditions. Epoxy resins (ER) are generally characterized by many outstanding properties such as the rigidity, high temperature performance, chemical resistance, good adhesive properties, and also compatibility with wide variety of the known curing agents [2]. However, the major drawback of epoxy adhesives is their brittleness. A new approach aiming to overcome this basic problem is related to the use of elastomeric fillers with small particle size. These particles embedded in polymer matrix have attracted increasing interest because of the unique mechanical and thermal properties displayed by elastomers. Addition of limited amounts of an adequate reactive liquid rubber can improve their resilience and toughness through one or more of the bonding mechanisms [3].

The approach demonstrates the potential to change characteristics of thermosetting and thermoplastic polymers fundamentally to improve their general performance. The mechanical properties obtained for composite due to the presence of minute rubbery particles are expected to be highly improved compared to that for composite with large rubbery particle size. However, the unique modified matrix effect can only be effective, if the tiny particles are well dispersed in the surrounding polymer matrix. It is reported that a considerable amount of improvement in mechanical properties can be achieved using very low amount of rubbery modifier loadings [1]. The dispersion method for the rubber particle incorporation in polymer matrix must be very vital footstep and key point to receive the desired material properties. A proper dispersion process is necessary in order to transfer the rubber particles from the agglomerated state into a homogeneously dispersed state. Chemical methods are able to generate individual and non-agglomerated rubbery particles "in situ" within a thermosetting/thermoplastic polymer. The expected overall properties of the obtained composite may open the way towards new applications of high performance polymers, leading to an innovative product development in the automotive industry, electronics for coatings and many other applications. The resin can form a cross-linked network structure with relatively high stiffness and glass transition temperature (Tg). Ozturk et al. [4] employed some of the HTPB rubbers to improve the epoxy thermal and mechanical properties and also to toughen its thermoset matrix.

The obvious characteristic of these rubbers is their immiscibility in the epoxy resin and consequently their separation from the major epoxy matrix throughout the cure reaction. In the literature, few information is available concerning the structure-property relationship of the epoxy-HTPB system.

In this paper, mechanical and thermal properties of the selected neat and modified resins are presented. Morphology and other related properties of formulations have already been presented in a previous work for the authors [5].

Crosslinking and particle/matrix interactions and their effects on the glass transition temperature of the thermoset are also investigated. 


\section{Experimental}

\subsection{Materials}

The employed epoxy resin used was liquid diglycidyl ether of bisphenol A (DGEBA) (under the trade name, EPON 828) with a number average-molecular weight of 380 and an epoxide equivalent of 180-195 g/equiv produced by Hexion Chemical Co. A polyamide (under the trade name, VERSAMID 125) with an amine value of about $350 \mathrm{mgKOH} / \mathrm{g}$ was used as curative. The employed liquid hydroxyl terminated polybutadiene (USA origin) was of 3000 as a number average molecular weight and a hydroxyl number of $0.8 \mathrm{~g} / \mathrm{m}$. equiv. Structure of the employed chemicals is given in (Figure 1)

\subsection{Curing procedure}

The neat sample was prepared using mixtures of the EPON 828 as a resin and VERSAMID125 as a hardener. The modified samples were prepared as follows: the proper amount of EPON 828 was first degassed for $60 \mathrm{~min}$ in a vacuum oven at $80^{\circ} \mathrm{C}$. The needed rubber (HTPB) was also degassed separately under the same conditions. Both components were mixed and then the curing agent was added (see Table 1). The mixture was gently stirred for about $5 \mathrm{~min}$ to ensure proper dispersion of the hardener, then degassed for $5 \mathrm{~min}$ and finally poured into the appropriated moulds for mechanical and thermal testing. Curing was then performed at $100{ }^{\circ} \mathrm{C}$ for $120 \mathrm{~min}$.

\subsection{Characterization}

\subsubsection{Mechanical testing}

Stress-strain relations were obtained experimentally for each of the prepared formulations. The Zwick1487 universal test machine was used for carrying out tensile tests, at a crosshead speed of $5.08 \mathrm{~cm} / \mathrm{min}$. The tensile test was carried out for five samples of each prepared formulation and the mean value of the obtained results was recorded.

Zwick Durometer Hardness Tester model 3102 was used to determine the relative hardness of the prepared samples. The test specimens were generally $6.4 \mathrm{~mm}(1 / 4 \mathrm{in})$ thick. The test measured the penetration of a specified indentor into the material under specified conditions of force and time, and the hardness numbers were derived from the given scale. The specimen was first placed on a hard flat surface. The indentor for the instrument was then pressed into the specimen making sure that it must be parallel to the surface. The hardness has to be read within 30 second of firm contact with the specimen.

Flexural tests were performed with rectangular samples according to ASTM D-790 using the tensile test machine model LLOYD LRX5K fitted with a three-point bending fixture at a crosshead speed of $0.5 \mathrm{~mm} / \mathrm{s}$. The dimensions of the samples were $3.2 \times 12.7 \times 125 \mathrm{~mm}$ and the span to thickness ratio was set at $\mathrm{L} / \mathrm{D}=25$ in all cases

The results are expressed in Mega Pascal (MPa), which is the average of the results from five samples. Compression tests were performed with cylindrical shaped samples according to ASTM D695 using the Zwick 1487 universal test machine. The dimensions of the samples are typically $12.7 \mathrm{~mm}(1 / 2 \mathrm{in})$ in diameter and $25.4 \mathrm{~mm}$ ( $1 \mathrm{in})$ long. The specimen was placed between compressive plates so that it became parallel to the surface. The specimen was compressed at a uniform rate. The maximum load was recorded along with stress-strain data. The results are expressed in $\mathrm{kg}_{f} / \mathrm{cm}^{2}$, which is the average of the results from five samples. 


\subsubsection{Differential scanning calorimetry (DSC)}

Differential scanning calorimetry (DSC) was performed using a Linseis differential scanning calorimetry apparatus model: DSC-L63/45. The cure conditions were determined using the dynamic mode at $20^{\circ} \mathrm{C} / \mathrm{min}$ so as to verify the time for complete curing. About $10-15 \mathrm{mg}$ of samples in aluminum pans were used for each measurement. The heat evolved during the reaction of the mixture was directly determined by integration of the exothermic peaks.

\section{Results and discussion}

\subsection{Mechanical properties}

Stress-strain behavior of the modified epoxies is shown in Figure (2a-2b). The tensile properties were gradually increased and maxima were almost achieved at a limiting rubber content of about $2.5 \%$. The tensile strength decreases beyond this limiting value and this may be related to the expected lowering in the cross-linking density. The interaction between the formed rubbery particles and the matrix may explain the improvements accompanying addition of a modifying rubber while the particle-particle interaction may explain the decrease taking place beyond the found maxima. Beyond the observed maxima, the volume fraction of the dispersed phase may become more effective than the mentioned interactions. The HTPB is less compatible with the resin and consequently the volume fraction of the dispersed rubber becomes significant, so that it can reduce the interaction in the epoxy matrix. The recorded increase in elongation at break may indicate the adhesion taking place via chemical reactions which may take place between the rubbery phase and the matrix, and incorporation of the diene backbone in the epoxy chains [5]. The various mechanical properties for different rubber loadings are represented in Table 2.

Results of the shore D hardness tests came in agreement with tensile properties (ee figure 3 ). These results directly express the resilience of the obtained modified epoxy samples.

The gradual increase in stiffness and flexural strength, as observed from Table 2 reveals that stresses can efficiently be transferred via the interface. Figure 4 depicts the obtained flexural properties for both the neat and rubber-modified resin samples. The flexural strength of the modified samples increases by increasing the rubber content until the limiting value reached. Very small amounts of rubber could be incorporated into the epoxy matrix and consequently flexibilize its thermoset network. The incorporated rubber may therefore explain the detected reduction in the flexural strength of the modified samples. Previous works on rubber-modified epoxies support this observation [3], [6], [7], [8] and [9].

The Compression results showed almost the same trend as both the tensile and flexural tests. Figure 5 presents the compression properties of both the neat and rubber-modified samples.

\subsection{DSC results}

The neat resin (P0) shows a glass transition temperature of about $102^{\circ} \mathrm{C}$ (Figure 6). This is very close to that stated in literature; $100^{\circ} \mathrm{C}$ in [10], and $102.0^{\circ} \mathrm{C}$ in [11]. The very slight increase in Tg which is observed in (P3) may be attributed to the decrease in mobility of the chain segments occurring due to the particle/matrix interactions.

Impeded chain mobility is possible as the HTPB particles are well dispersed in the matrix. The particle surface-to-surface distance is relatively small and consequently the chain segment movement is therefore restricted. Good adhesion of the HTPB particles with the surrounding polymer matrix may be regarded as an additional benefit to the dynamic modulus since it can hinder the molecular motion to some extend. The hard particles incorporated into the polymer would act as additional virtual network nodes. Hence, the slight increase in this 
Tg values may be related to the presence of the HTPB particles. The crosslink density is the key factor as it can control the $\mathrm{Tg}$ values for the normal thermoset polymer systems. The HTPB may also react with the epoxy-amine system forming an interfacial layer with significantly different segmental dynamics and this may also explain the recorded slight increase in the $\mathrm{Tg}$ values.

Effect of the HTPB is directly proportional to its percent in the network up to about $2.5 \%$ by weight. Above this rubber loading, poor distribution of the separated rubber particles may be one of the reasons for the recorded decrease in the Tg values (Figure 7).

The adsorption of matrix resin to the surface of the HTPB particles that shifted the nonstoichiometric mixture may be a second reason for the mentioned decrease $[12,13]$. The separated rubber particles which occupy a space between the reaction sites may impair the cross-linking reaction. This, in turn, reduces the cross-linking density of the cured systems. Thus the overall cross-linking density can be decreased by the incorporation of more rubber [14].

\section{Conclusion}

Functionally terminated polybutadiene liquid rubber has been incorporated into the epoxy resin matrix that undergoes curing with a polyamide hardener. Inclusions of rubber inside the epoxy network were found to cause a significant improvement in the mechanical properties, which in turns causes an enhancement of toughness. This will be attributed to the reduction in concentration of reacting species and viscosity effect on the addition of rubber. Addition of rubber causes lowering in cross-linking density of epoxy matrix during the cure polymerization reaction. Some amount of added rubber goes into the epoxy matrix and flexibilizes the brittle thermoset matrix. In that system, a toughening effect is observed as indicated by the best compression performance associated to improved flexural properties, because of the presence of rubber particles homogeneously dispersed inside the epoxy matrix. The $\mathrm{Tg}$ for the unmodified samples was about $100^{\circ} \mathrm{C}$. This value is very close to the published values concerning similar epoxy. Slight decrease in Tg has been observed for the modified formulations. This indicates the plasticization effect of the employed rubber additives. Addition of small percentage (about $2.5 \%$ ) of the HTPB rubber enhances the resin toughness without any adverse effects on either the mechanical or the thermal properties of the tested DGEBA based epoxy formulations.

\section{References}

[1] Amit Chatterjee, Muhammad S. Islam, "Fabrication and characterization of TiO2-epoxy nanocomposite". Materials Science and Engineering A 487 (2008), pp. 574-585.

[2] H. Lee and K. Neville (1st ed), 'Epoxy resins' in EPST vol. 6, The Epoxylite Corporation (1967) p. 209-271.

[3] F.L. Barcia, T.P. Amaral and B.G. Soares, Synthesis and properties of epoxy resin modified with epoxy-terminated liquid polybutadiene, Polymer 44 (2003), pp. 5811-5819.

[4] A. Ozturk, C. Kaynak and T. Tincer, Eur Polym J 37 (2001), p. 2353.

[5] Eyad S. Khalaf, Saeed M. Hassanein and Moustafa K. Hadhoud "Investigation of Mechanical Behavior for a Selected Rubber-Modified Epoxy Adhesive" 13th international conference on AEROSPACE SCIENCES \& AVIATION TECHNOLOGY, ASAT-13, May 26-28, 2009.

[6] F.L. Barcia, B.G. Soares, M. Gorelova and J.A. Cid, J Appl Polym Sci 74 (1999), p. 1424.

[7] H. Harrani, S. Fellahi and M. Baker, J Appl Polym Sci 71 (1999), p. 29. 
[8] I. Takao, Y. Naoto and M. Tomoi, Eur Polym J 28 (1992), p. 573.

[9] S. Manternal, J.P. Pascault and H. Sautereau In: C.K. Riew, Editor, Rubber toughened plastics, Advances in chemistry series vol. 222, American Chemical Society, Washington, DC (1989), p. 193.

[10] Edward M. Petrie "Epoxy adhesive formulations" McGraw - Hill 2008.

[11] J. M. Morancho and J. M. Salla, "Relaxation in a neat epoxy resin and in the same resin modified with a carboxyl-terminated copolymer". Journal of Non-Crystalline Solids, Volumes 235-237, 2 August 1998, pp. 596-599.

[12] H. Miyagawa, L.T. Drzal, Polymer 45 (2004) 5163.

[13] J. Palmese, University of Delaware, Dept. of Chemical Engineerings, Ph.D. Thesis, 1990.

[14] Raju Thomas, Ding Yumei, He Yuelong, Yang Le, Paula Moldenaers, Yang Weimin, Tibor Czigany, and Sabu Thomas, "Miscibility, morphology, thermal, and mechanical properties of a DGEBA based epoxy resin toughened with a liquid rubber". J.polymer. Volume 49, Issue 1, 10 January 2008, Pages 278-294. 
a- Epoxy resin (Epon-828)

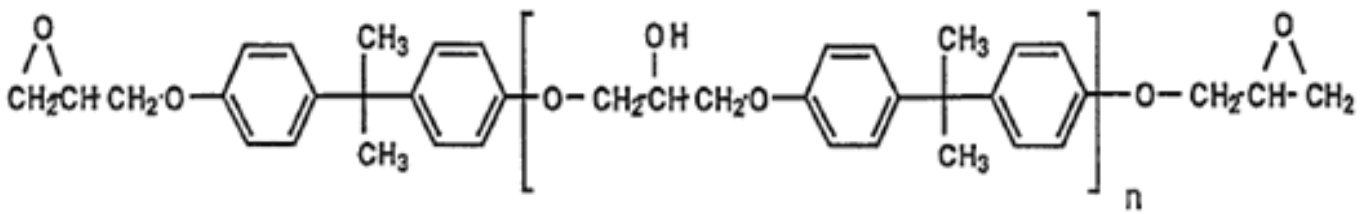

b-Versamid 125 (complex reaction product of acid dimer and diethylenetriamine)

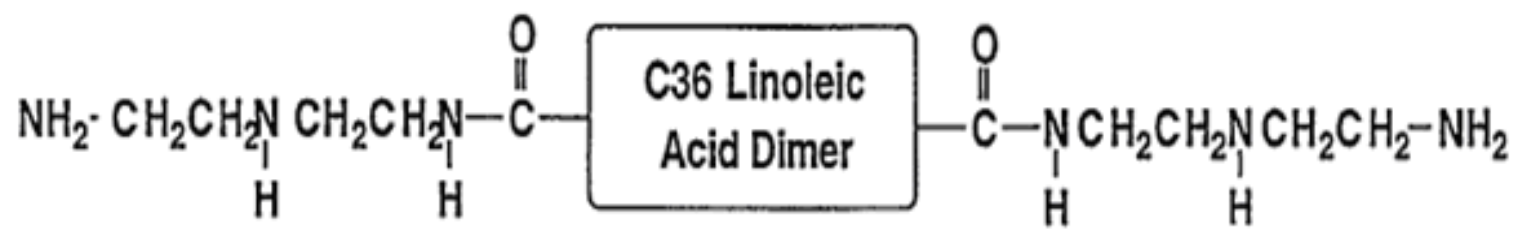

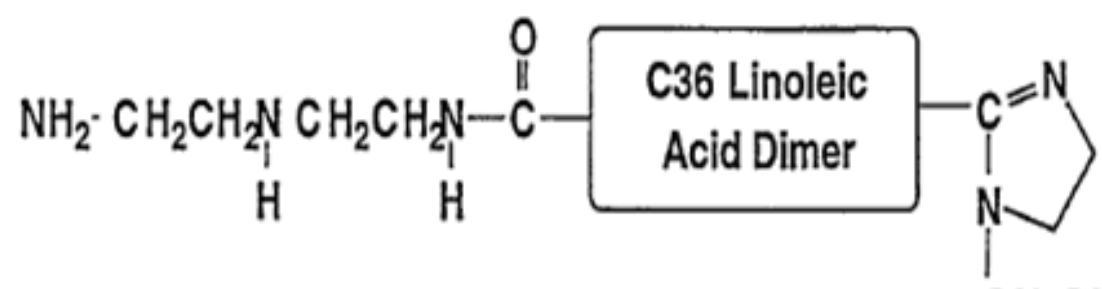

$\mathrm{CH}_{2} \mathrm{CH}_{2}-\mathrm{NH}_{2}$

c- HTPB

$\mathrm{HO}-(\mathrm{CH} 2-\mathrm{CH}=\mathrm{CH}-\mathrm{CH} 2) \mathrm{n}-\mathrm{OH}$

C36 Linoleic Acid Dimer

$=\mathrm{A}$ bulky, oil-compatible, C36 carbon group

Figure 1: Structure of compounds. 


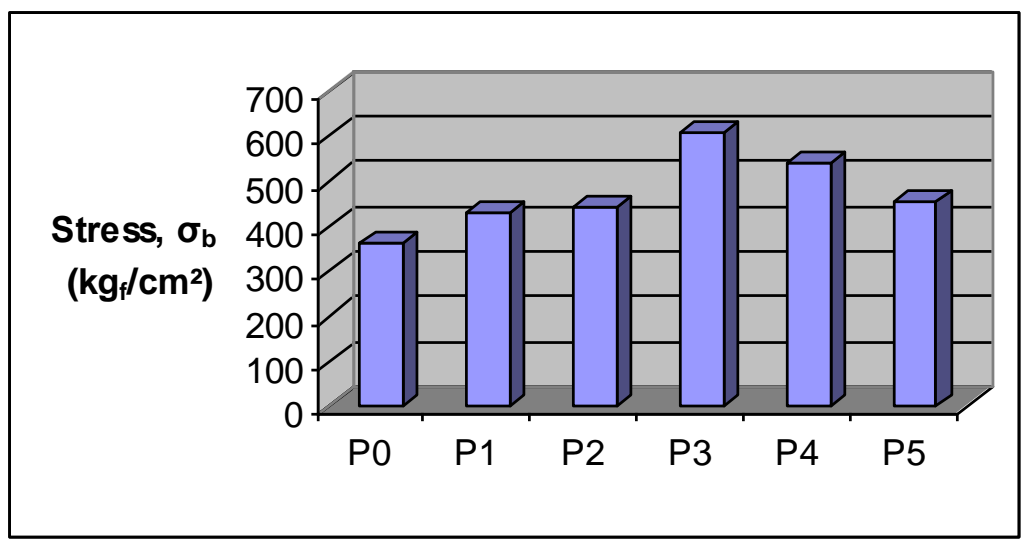

Figure 2a: Tensile Stress for neat and modified epoxies.

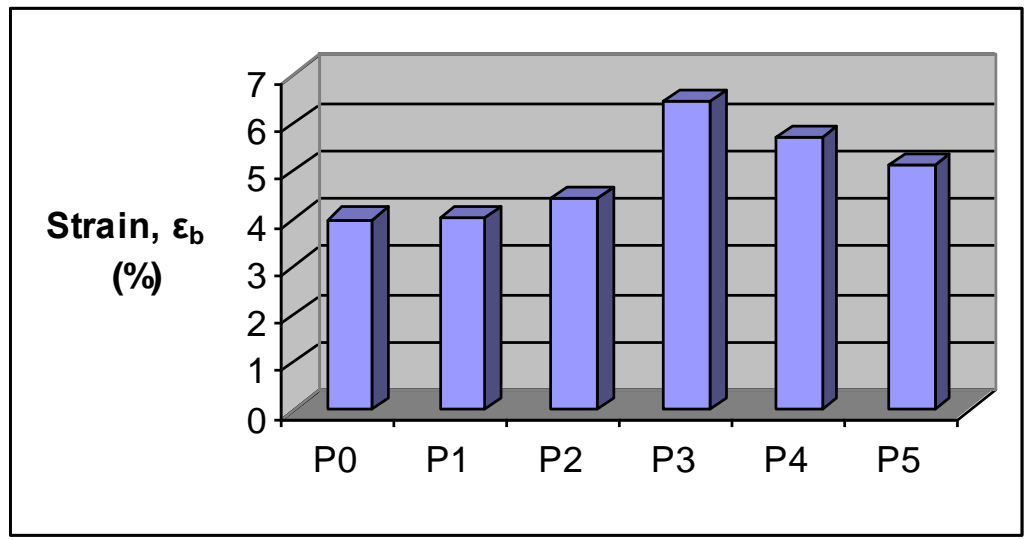

Figure 2b: Tensile Strain for neat and modified epoxies.

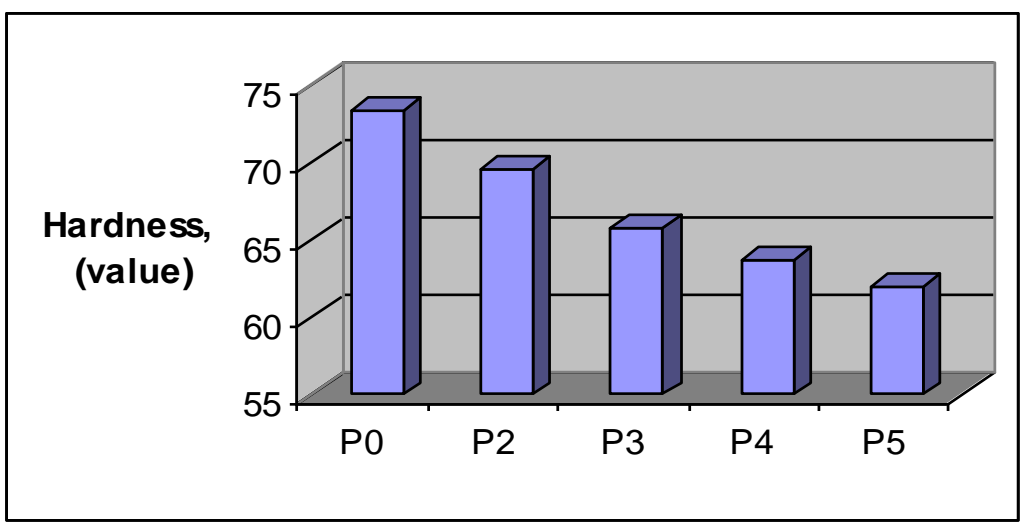

Figure 3: Hardness values for neat and modified epoxies. 


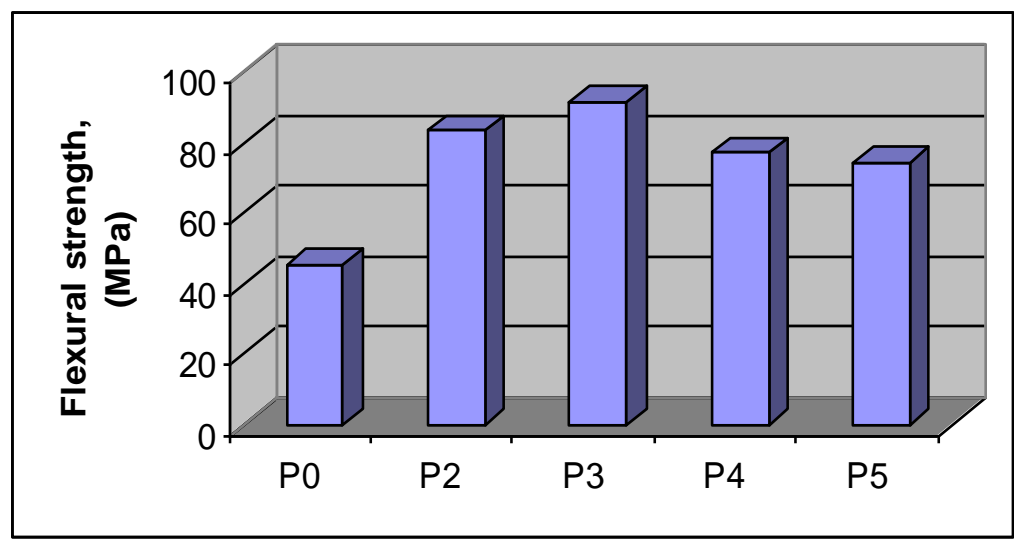

Figure 4: Flexural strength values for neat and modified epoxies.

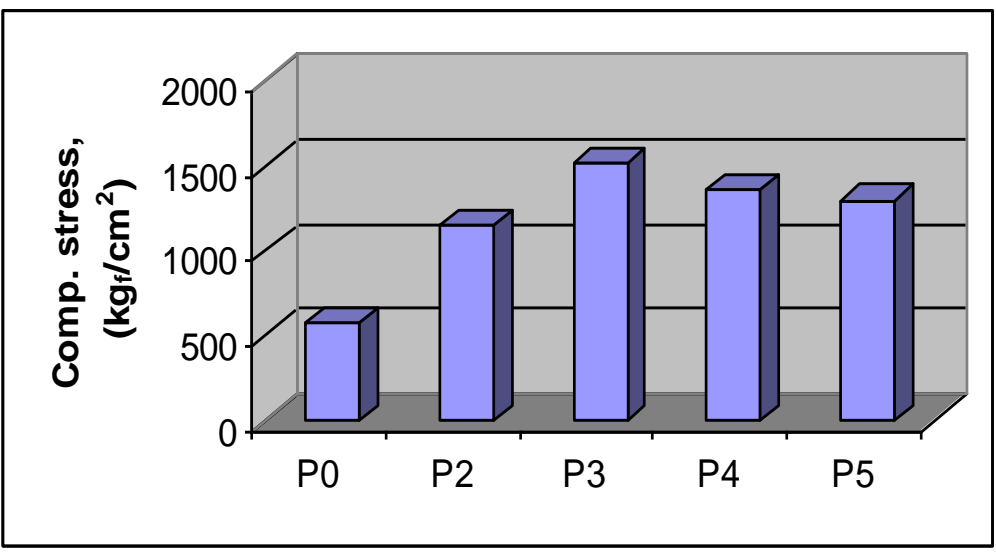

Figure 5: Compressive strength values for neat and modified epoxies.

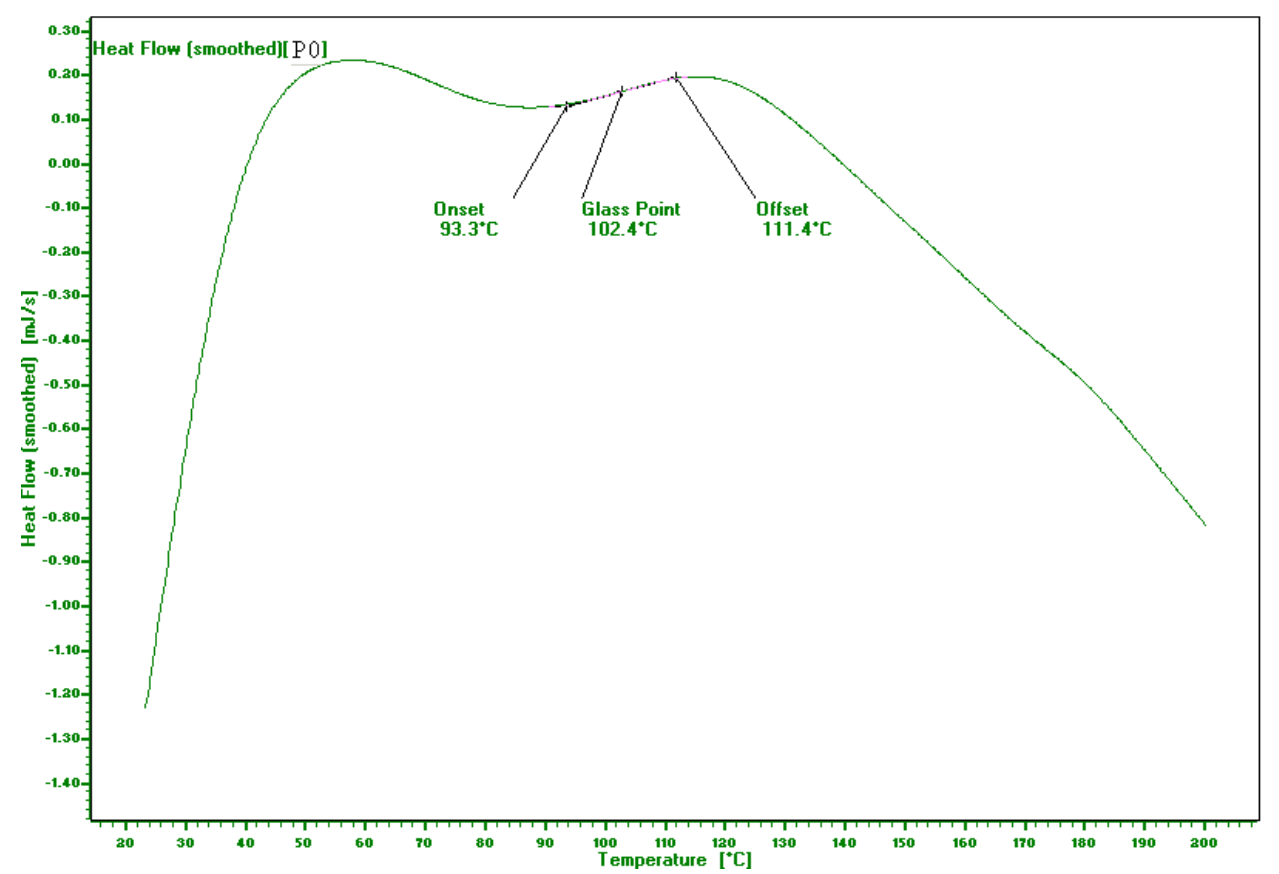

Figure 6: Differential scanning calorimetry (DSC) thermogram of neat epoxy (P0) at $10^{\circ} \mathrm{C} / \mathrm{min}$ heating rate 


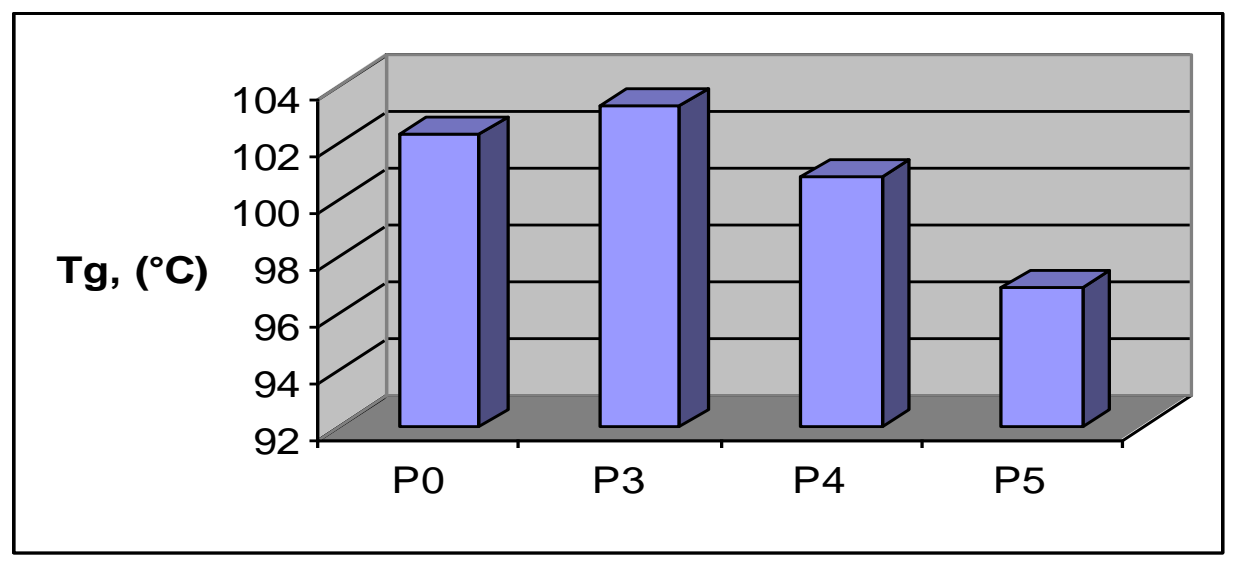

Figure 7: Tg values of neat and modified resins at different $\%$ of HTPB 1

Table 1: Neat and modified epoxy formulations

\begin{tabular}{|l|l|l|l|}
\hline Materials code & ER $(\mathrm{g})$ & Versamid 125 $(\mathrm{g})$ & HTPB $(\mathrm{g})$ \\
\hline P0 & 100 & 54 & $\mathbf{0}$ \\
\hline P1 & 100 & 54 & $\mathbf{0 . 7 5}$ \\
\hline P2 & 100 & 54 & 1.5 \\
\hline P3 & 100 & 54 & 2.5 \\
\hline P4 & 100 & 54 & 5 \\
\hline P5 & 100 & 54 & 10 \\
\hline
\end{tabular}

Table 2: Tensile properties at room temperature with different loadings of rubber cured at $100{ }^{\circ} \mathrm{C}$

\begin{tabular}{|l|l|l|l|l|l|}
\hline Characteristics & $\begin{array}{c}\text { Stress }\left(\boldsymbol{\sigma}_{\mathbf{b}}\right) \\
\left(\mathbf{k g}_{\mathbf{f}} / \mathbf{c m}^{\mathbf{2}}\right)\end{array}$ & $\begin{array}{c}\text { Strain }\left(\boldsymbol{\varepsilon}_{\mathbf{b}}\right) \\
(\mathbf{\%})\end{array}$ & $\begin{array}{c}\text { Hardness } \\
(\mathbf{v a l u e})\end{array}$ & $\begin{array}{c}\text { Flexural } \\
\text { Strength } \\
(\mathbf{M P a})\end{array}$ & $\begin{array}{c}\text { Compressive } \\
\text { Strength } \\
\left(\mathbf{k g}_{\mathbf{f}} / \mathbf{c m}^{2} \mathbf{)}\right.\end{array}$ \\
\hline P0 & 365 & 3.99 & 73.33 & 45.50 & 576.96 \\
\hline P1 & 430 & 4.02 & - & - & - \\
\hline P2 & 444 & 4.44 & 69.50 & 83.18 & 1154.48 \\
\hline P3 & 609 & 6.46 & 65.75 & 91.23 & 1519.16 \\
\hline P4 & 540. & 5.72 & 63.66 & 77.07 & 1356.34 \\
\hline P5 & 451 & 5.13 & 62.00 & 74.20 & 1296.90 \\
\hline
\end{tabular}


Military Technical College

Kobry El-Kobbah, Cairo, Egypt

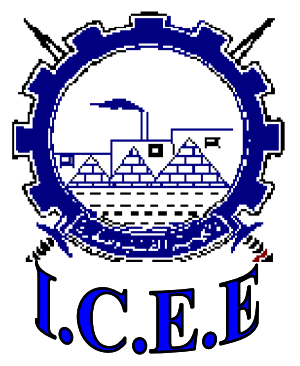

$5^{\text {th }}$ International Conference on

Chemical \& Environmental Engineering 25 - 27 May, 2010. 